\title{
Monitoring for Circumstance of Wildfire Occurrence in Kalimantan by Using Satellite Remote Sensing Data Based on GIS
}

\author{
Naru Takayama \\ Faculty of Engineering, Osaka Institute of Technology, Osaka, Japan \\ E-mail: naru.takayama@oit.ac.jp
}

\begin{abstract}
Much carbon fixed by forest is emitting as $\mathrm{CO} 2$ due to occurrence of wildfire which caused by artificially or naturally. Kalimantan region is one of hot spot the forestry and bio-divergence, however, it is rapidly losing in recent, because deforestation and occurrence of wildfire. Satellite remote sensing is very effective tool to monitor circumstance of ground surface, routinely and extensively. In this report, we tried land cover classification to discriminate burned area for aiming to clarify spatial distribution of frequency of wildfire occurrence. As a result, we could classify land cover to seven types as follow based on discriminate analysis by using multi-band from visible to short wave infra-red acquired from Landsat 8 satellite image; 1 . Open water area 2. Cumulus 3. Cirrus or Haze 4. Cloud shadow 5. Vegetation area 6. Other type area 9. No-data. The category 6 of "Other type area" contains city area, bare soil, burned area and edge of cumulus, so we could expect to extract the burned place pixels from this categorical pixels.
\end{abstract}

Keywords: Satellite remote sensing, GIS, Wildfire, Land cover, Peat swamp forest.

\section{Introduction}

Republic of Indonesia have huge forest area that is 8th in the world, also, one of the most biodivergence region. According to recent study, however, more than 60,200 square $\mathrm{km}$ of forest have lost during 2000 to 2012 in Indonesia1). Its area is equivalent approximate to Tasmania Island in Australia. $76 \%$ of greenhouse gas emitted artificially is CO2, and $10.8 \%$ of it caused by deforestation and changing land usage and so on2), according to 5th IPCC Report. Deforestation is mainly result of wood or charcoal acquisition, settlement, road building, slash-and-burn agriculture etc. On the one hand, it could be cause of degradation of global environment due to promote global warming, desertification and bio-divergence loss. There is a lot of region in the world where a much carbon fixed by forest is emitting as $\mathrm{CO} 2$ due to occurrence of wildfire which caused by artificially or naturally. Area of forest of the world is 3.999 billion ha, however, it shares $30.6 \%$ whole of land3). Monitoring of such huge forest regions is not easy by only from ground level. Satellite remote sensing is very effective tool to monitor ground environments, routinely and extensively, over huge area whole of the earth. In this report, I would like to introduce for monitoring of circumstance of wildfire occurrences around Kalimantan area based on Landsat-satellite-data by using Geographic Information System (GIS). 


\section{Methodology}

\section{A. Study area and field survey}

We have done field surveys in the three periods, from Aug-30 to Sep-2 in 2015, from Feb-23 to 25 in 2016 and from Feb-12 to Mar-15 in 2017. We have taken some geo-photos by using a GPSCamera (EOS-kiss; Canon) in several places. Also, aero-photos have been taken in the seven places of after burned area by using UAV (Phantom3-standard; DJI) from 100m height in the survey period of 2017. We made one integrated aero-image from aero-photos which took each site, and after orthogeometric correction, they were imported to GIS. The survey area of central Kalimantan was shown in figure 1 . The range approximately, covered $65 \mathrm{~km}$ of north, $16 \mathrm{~km}$ of south, $21 \mathrm{~km}$ of east and $18 \mathrm{~km}$ of west directions from a centre of Palangkaraya City. These surveys were conducted as the International Project Based Learning Program (IPBL) and the International Collaborating Study Program (ICSP) which were achieved by Osaka Institute of Technology (OIT) and University of Palangkaraya (UPR).

B. Geographical data

We prepared preliminarily, the GIS database which contain some geographical information around Kalimantan region before starting field surveys by using GIS software (ArcGIS ver.10.4; ESRI). Some kind of geographical data can obtain via internet, and these were imported to GIS as layer structure with geo-photos which took during the field surveys. Contents of acquisition data and its simple treatments are the following.

- National country and world maps; Global Administrative Areas (Boundary) http://www.gadm.org/country

This data could obtain by shape-files which is standard format to record vector type geographical data such as point, line or polygon.

- GTOPO30; 30 arc-second Digital Elevation Model U.S. Geological Survey (USGS)

https://lta.cr.usgs.gov/GTOPO30

This data could obtain as DEM files from USGS web site.

- 2010 Digital Forest Land Use, Land Cover and Administrative Boundary Maps WEBGIS Kehutanan

Ministry of Forestry of Indonesia

http://webgis.dephut.go.id/ditplanjs/index.html

This data could obtain as layer-files like a geo-image.

- Road (jalan) and Canal and river (sungai) shape files.

UPR provided these data with OIT.

- Base map

http://www.arcgis.com/home/group.html?id=702026e41f6

641fb85da88efe79dc166\# Overview

This data is providing by ESRI online. We can use very conveniently, to know information of land cover, because, basic road map, world atlas and world imagery high resolution aero-image are included. 


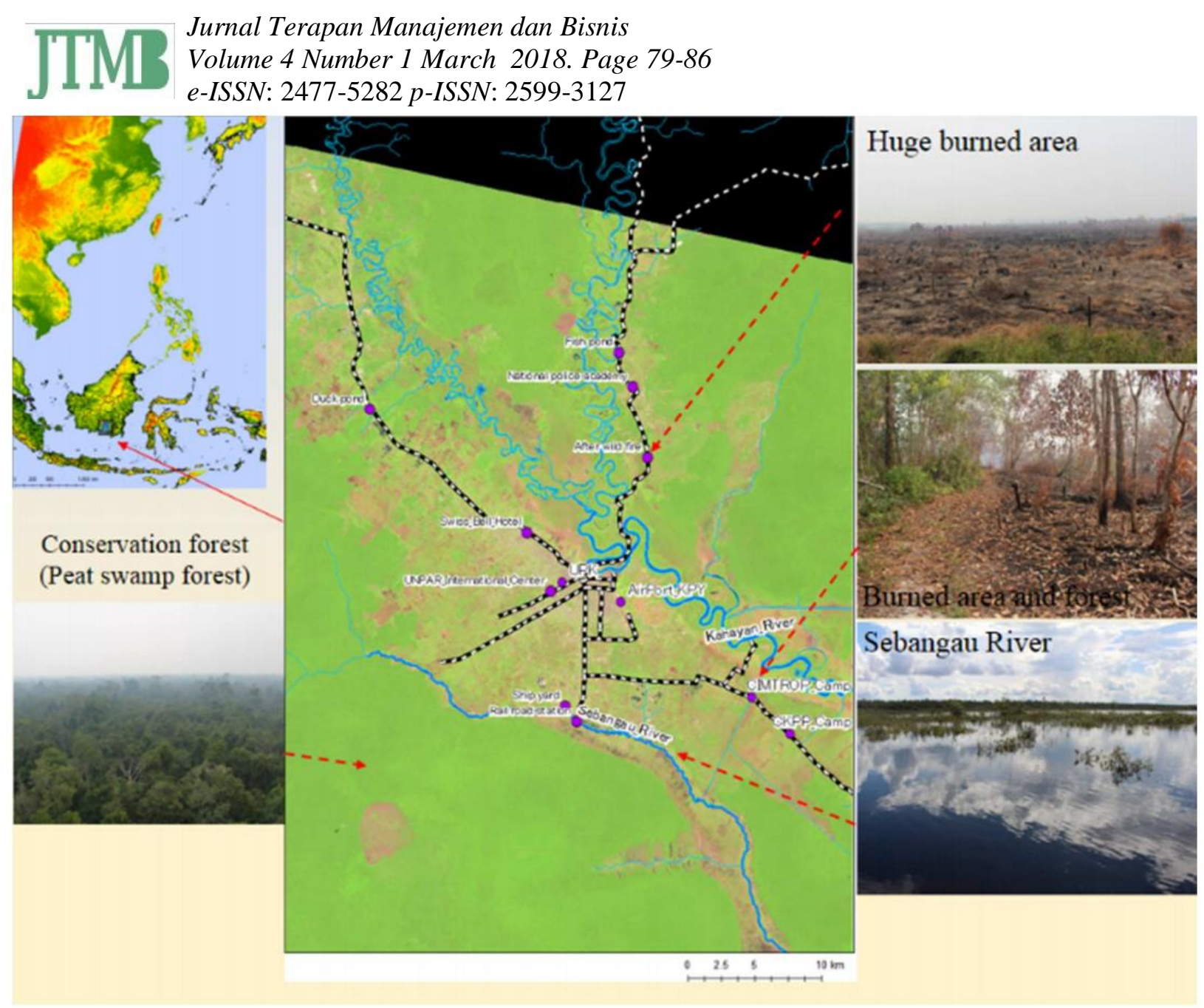

Fig. 1 The survey area of central Kalimantan around Palangkaraya.

\section{Satellite remote sensing data}

We used the scenes covered over the Kalimantan region which was acquisitioned by Landsat satellites 5-TM, 7-ETM+ and 8-OLI. Landsat are satellites which launched by U.S.A. This satellite series continue to observe land cover environment, during over 40 years, from 1972 when No.1 launched, to No.8 of recent. Landsat goes around on polar orbit 15 times per day, and pass the same area every 16 days, accurately. Such orbit is defined as "Sub-recurrent Orbit", and satellites can observe, regularly, whole of earth from this orbit, so it is useful for environmental observation of land surface. Several kind of sensors have mounted generally, on each satellite, according to purpose of observation. The Operational Land Imager (OLI) on Landsat-8 can measure spectral reflectance of 4 visible bands, 1 near infrared band and 3 short wave infrared bands with $30 \mathrm{~m}$ spatial resolution. Figure 2 shows feature of multispectral band reflectance from vegetation (place on last page). Healthy vegetation leaves reflect green light which around $550 \mathrm{~nm}$ of wavelength spectral band very well, so we can see plant leaves as recognition of green color. On the other hand, active green leaves absorb much red light for photosynthesis, though near infrared band is higher reflected. We can monitor a circumstance of land surface and activity of vegetation by using a feature of spectral band reflectance on subject materials. 
so

\section{EXPLOITING SPECTRAL RESPONSE CURVES}

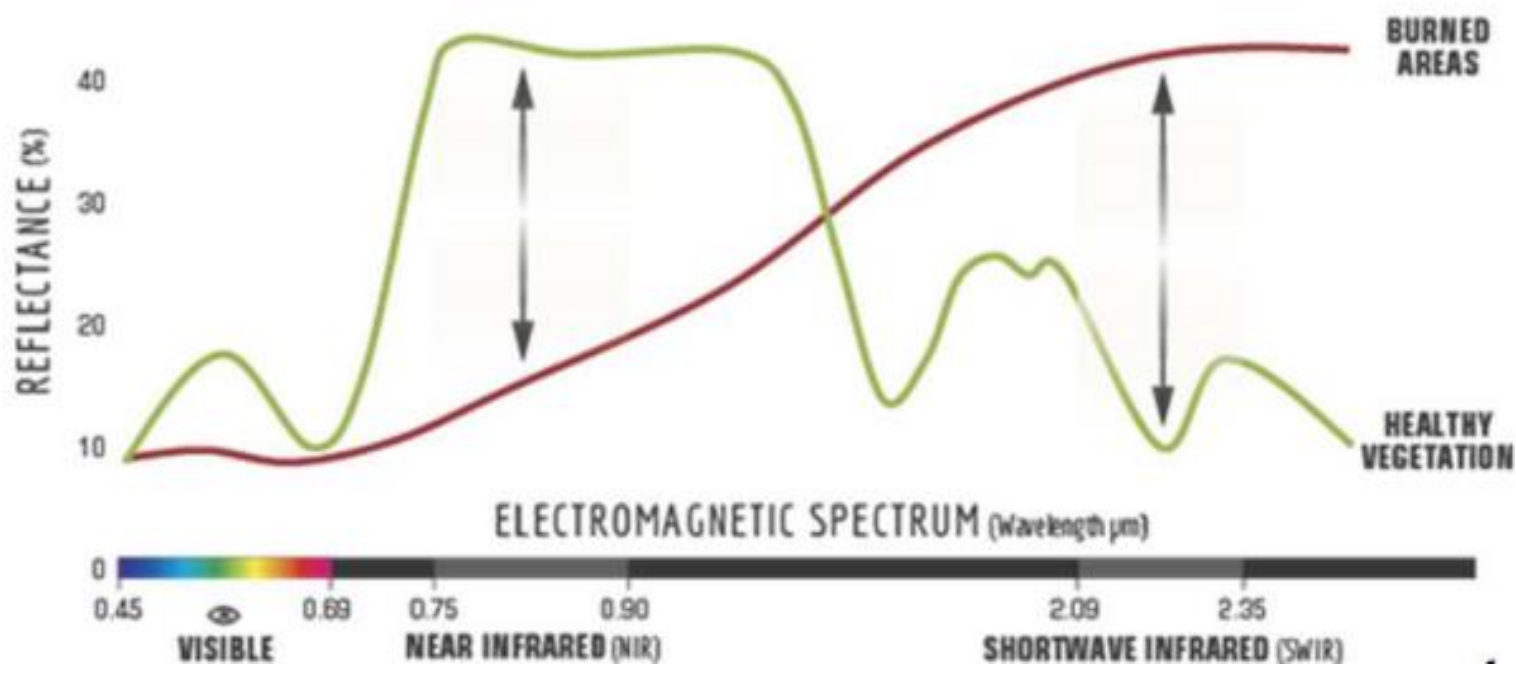

Fig. 2 Exploiting spectral response curves.

\section{Classification of Land Cover}

We set initially, the seven kinds of land cover category as open water area, cloud, cloud shadow, burned area and bare soil, forest, grassland and city area, and tried to classify each pixel of Landsat to seven categories. The scene of Landsat-8 on Path 118 Row 62 in Aug-3 2015 was used, because its acquisition day was close to first field survey and also good weather condition. Sample points about 10 to 20 for each land cover category were set as shape file on GIS based on referencing results of field survey and false color image of the scene. The reflectance of each band, the mean of visible bands, the standard deviation of visible bands, Normalized Vegetation Index (NDVI) and Normalized Burn Ratio (NBR) were calculated as explanatory values at each pixel. All explanatory values were read on the sample points of each land cover category, and were used for discriminant analysis of land cover classification. Discriminant formula was calculated to divide the dummy value for each land cover category by using all sample points data. We tried to find the combination of explanatory values which all explanatory values are significant as 95 percent significance level and the formula have been a maximum percentage of correct judge.

\section{Finding and Discussion}

\section{A. Discrimination and masking of cloud and cloud shadow}

We could obtain the discriminant formulas for cloud and cloud shadow by using three and five explanatory variables, respectively. Its ratios of (correct and incorrect) was (100\% and $0 \%)$ and $(99.2 \%$ and $0.3 \%$ ), respectively. Although, spatial distribution of cloud and cloud shadow is different for each scene, masking of them for another scenes were possible by applying the discriminant formulas based on the scene of Aug-3 2015. However, it was difficult that discriminate between cirrus, haze and edge of cumulus, because feature of multispectral reflectance are different between three types of cloud. Haze is often occurring with wildfire, especially dry season. So, we classified clouds to "Cumulus" and "Cirrus and haze", based on unsupervised classification, for each scene. We could masking of cumulus by to set a threshold in the first principle component of all OLI band (except for band 8) reflectance, because, cumulus have higher reflectance for all visible, near infrared and shortwave infrared bands. Band 9 have only mounted on Landsat 8 to discriminate cirrus. Band 9 have well sensitivity for haze, too, so we set a threshold of band 9 reflectance to discriminate and to do masking cirrus and haze. 


\section{Jurnal Terapan Manajemen dan Bisnis \\ Volume 4 Number 1 March 2018. Page 79-86 \\ e-ISSN: 2477-5282 p-ISSN: 2599-3127}

B. Discrimination of places after wildfire occurring

As a result of discriminant analysis for five categories of land cover type, the discriminant formulas with 6 of explanatory values could be obtained for open water area and city area. Its ratios of (correct and incorrect) was (100\% and $0 \%)$ and (95.3\% and $4.7 \%)$, respectively. We could find out the range around Sebangau river, where water flooding in rainy season (from Oct. to Mar.) but changing to grassland or wildfire occurrence in dry season (from Apr. to Sep.), by discriminant analysis for "open water area". On the other hand, the place where were judged as "city area" have contained both burned places and bare soil places, including the huge burned area just in field survey. The discriminant formulas with 3 and 2 of explanatory values could be obtained for "forest" and "grassland", respectively. Its ratios of (correct and incorrect) was (90.6\% and $11.4 \%)$ and $(66.4 \%$ and $30.8 \%$ ), respectively, so, incorrect judgement was a little remarkable. We could not obtain a significant discriminant formula for "burned area and bare soil". It was consequently difficult that discriminate vegetation area to forest or grassland. Also it was similarly difficult that discriminate between city area and burned area and bare soil, by using OLI sensor in Central Kalimantan region.

C. Estimation of Land cover type

Finally, we set seven kinds of land cover category as follow, and classified each pixel of Landsat scene. 1. Open water area 2. Cumulus 3. Cirrus or Haze 4. Cloud shadow 5. Vegetation area 6. Other type area 9. No-data. The other type area contains city area, bare soil, burned area and edge of cumulus, so we have to extract the burned place pixels from this categorical pixels. Figure 3 shows the false color image at 16 Mar. 2016 over the survey area around Palangkaraya City. Figure 4 shows the results of land cover classification over the same area in Central Kalimantan. Left one is at 3 Aug. 2015 in dry season, and right one is at 16 Mar. 2016 in rainy season. Classifying "the open water area" is for water flooding during rainy season in the area between edge of conservation forest and Sebangau River. As a result of analysis, new huge burned area seem to generated, in east side of the survey site of huge burned area at north of Palangkaraya City, also, in the part of conservation forest at the south. Respirator disease with haze became serious problem because a lot of wildfire occurred in large scale at the end of dry season in 2015 of central Kalimantan. It was estimated that these wildfire occurred during 20 Sep. to 23 Nov. 2015 based on analysis of Landsat 8 satellite images. We are just planning the analysis to clarify a spatial distribution of wildfire occurrence frequency in the whole of Kalimantan region, by using Landsat archives. 


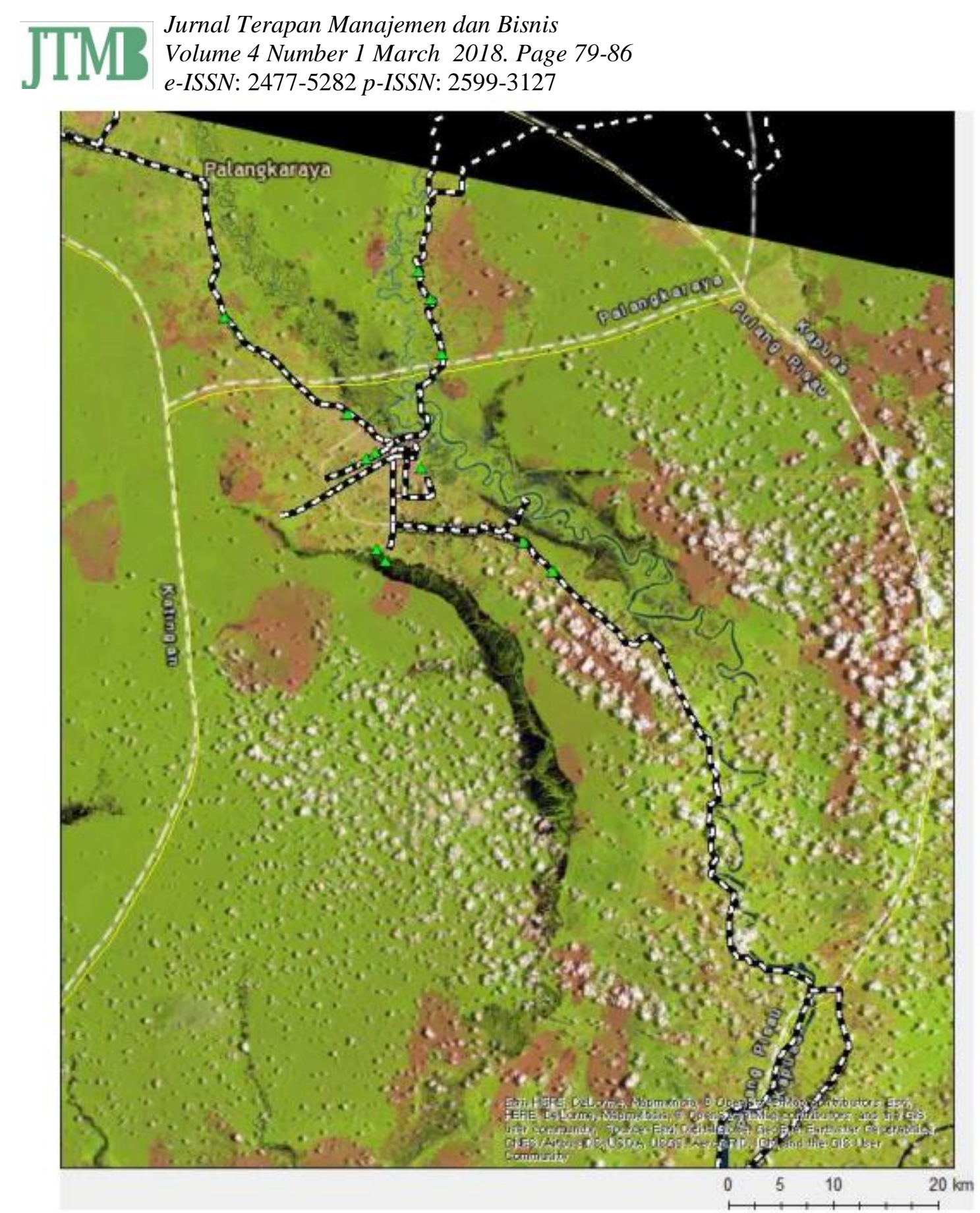

Fig. 3 False image of Landsat 8 over the survey area at 16 Mar. 2016. 


\section{JTMB \\ Jurnal Terapan Manajemen dan Bisnis \\ Volume 4 Number 1 March 2018. Page 79-86 \\ e-ISSN: 2477-5282 p-ISSN: 2599-3127}
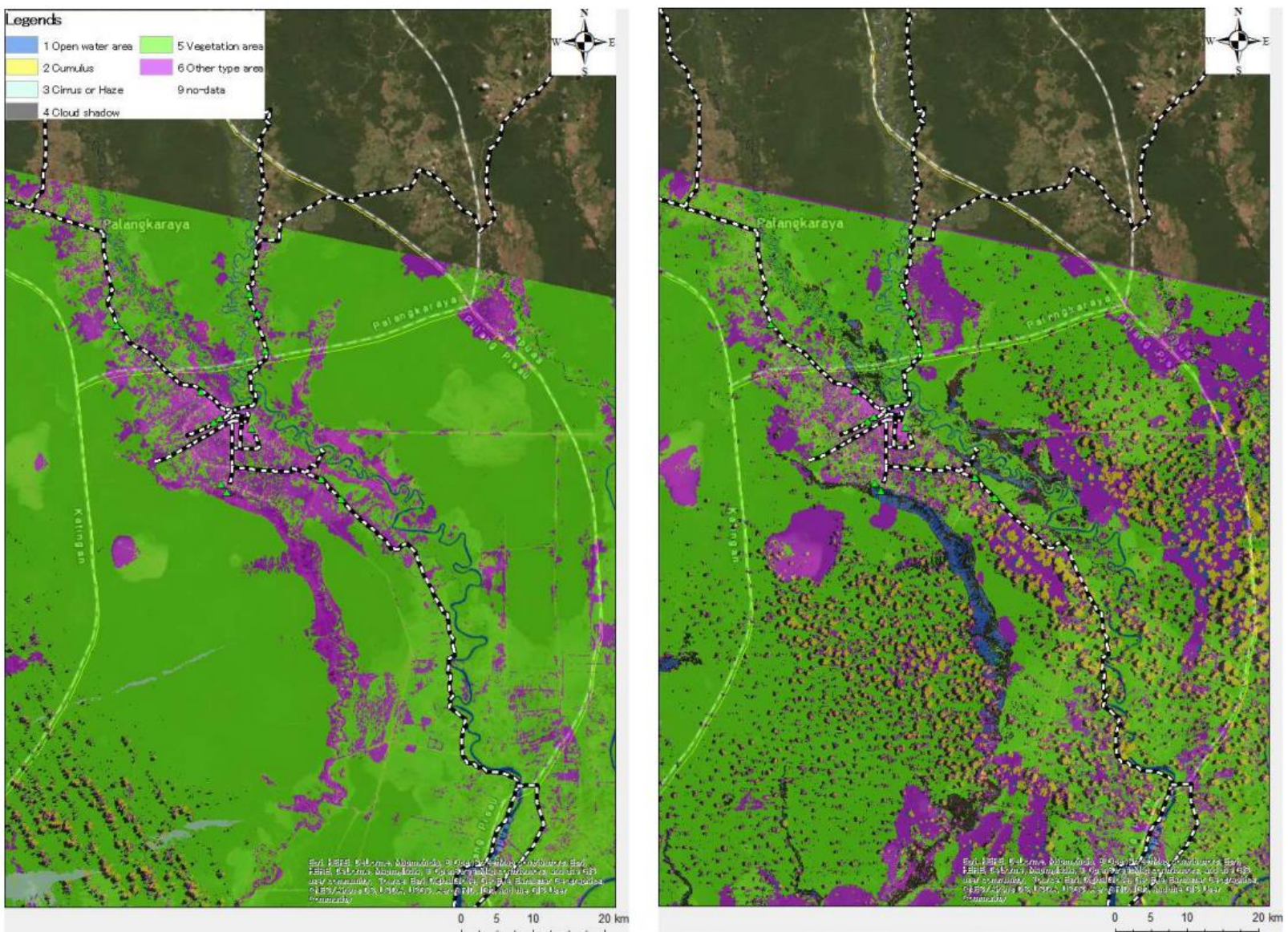

Fig. 4 Classification of land cover around Palangkaraya City (left; 3 Aug. 2015, right; 16 Mar. 2016)

\section{Conclusion}

Much carbon fixed by forest is emitting as $\mathrm{CO} 2$ due to occurrence of wildfire which caused by artificially or naturally. Kalimantan region is one of hot spot the forestry and bio-divergence, however, it is rapidly losing in recent, because deforestation and occurrence of wildfire. Satellite remote sensing is very effective tool to monitor ground environments, routinely and extensively, over such huge area. In this report, we could classify seven land cover types as follow based on discriminant analysis by using Landsat 8 OLI. We have the plan to discriminate burned area for aiming to clarify spatial distribution of frequency of satellite image; 1 . Open water area 2. Cumulus 3. Cirrus or Haze 4. Cloud shadow 5. Vegetation area 6. Other type area 9. No-data. The category 6 of "other type area" contains city area, bare soil, burned area and edge of cumulus, so we could expect to extract the burned place pixels from this categorical pixels.

\section{Acknowledgment}

This study has achieved as part of IPBL Program collaborated Osaka Institute of Technology and University of Palangkaraya.

\section{REFERENCES}

B. A. Morgono, P. V. Potapov, S. TURUbanova, F. Stolle and M. C. Hansen, “Primary forest cover loss in Indonesia over 2000-2012" nature climate change, vol. 29, pp. 1-6, Jun. 2014.

Japan Meteorological Agency. (2017) Knowledge of Global Warming homepage on JMA. [Online]. Available: http://www.data.jma.go.jp/cpdinfo/chishiki_ondanka/p04.html

Ministry of Agriculture, Forestry and Fisheries. (2015) Forest Resource Assessment homepage on MAFF. [Online]. Available: http://www.rinya.maff.go.jp/j/kaigai/attach/pdf/index-2.pdf. 
Jurnal Terapan Manajemen dan Bisnis

Volume 4 Number 1 March 2018. Page 79-86

e-ISSN: 2477-5282 p-ISSN: 2599-3127

(http://agribotix.com/blog/2014/6/10/misconceptionsabout-uav-collected-ndvi-imagery-and-theagribotixexperience-in-ground-truthing-these-images-for-agriculture) 